\title{
JUAN JOSÉ SAER: UMA LITERATURA ATORDOANTE*
}

\author{
Márcia Rosa**
}

Resumo: Este trabalbo tece alguns comentários sobre a praxis escritural do argentino Juan José Saer, evidenciando aí uma 'disciplina do estranhamento' $e$ 'uma estética das sensações' que levam o leitor a um atordoamento. Uma atençäo especial é dada ao livro Ninguém, Nada, Nunca.

"Para ser verdadeira, a bistoricidade deve revelar sua carga de natureza, deve saber que a natureza está nela e a sustém."J.J.Saer

Se nos familiarizarmos com as obras dos grandes escritores latino-americanos do século $\mathrm{XX}$, descobriremos não só que têm pouco ou nada em comum, senão que também se opõem violentamente uns aos outros. No entanto, todos, sem dúvida, possuem em seus escritos um elemento: "(...) a vontade de construir uma obra pessoal, um discurso único, retomado sem cessar para ser enriquecido, afinado, individualizado quanto ao estilo (...)." (SAER, 1997b:275)

Quem assim o afirma não é outro senão o autor de Ninguém, Nada, Nunca, (1980), Juan José Saer. Argentino, radicado na França há mais de trinta anos, o ficcionista, de estilo hiperrealista, acredita que um escritor não representa, enquanto escri-

\footnotetext{
* Recebido para publicação em março de 2002.

** Doutoranda em Literatura Comparada no Pós-Lit da Faculdade de Letras/UFMG.
} 
tor, qualquer tipo de interesses ideológicos e dogmas estéticos ou políticos, não podendo, portanto, "(...) definir-se por um elemento estranho à praxis da escritura." (SAER,1997b:291) Sendo assim, para esse professor de Teoria da Literatura na Universidade de Rennes, ser latino não o põe à margem da constatação de que:

(...) ser narrador exige uma enorme capacidade de disponibilidade, de incerteza e de abandono e isto é válido para todos os narradores, seja qual for sua nacionalidade. Todos os narradores vivem na mesma pátria: a espessa selva virgem do real. (SAER, 1997b:271)

Por conseguinte, interessa-nos assinalar alguns dos modos pelos quais Saer trata, pela escritura, essa 'espessa selva do real'.

\section{1- Prosa/poesia: uma disciplina do estranhamento}

Compartilhando um traço presente na literatura contemporânea - a anulação da noção de gênero -, a literatura saeriana pode ser apresentada como 'um poema em prosa'. (CORBATTA, 1999:98) Esfumadas as distinções entre uma e outra, torna-se então pertinente atribuir à prosa de Saer as concepções que ele mesmo apresenta "Sobre la poesia". (1968)

Para o autor de El concepto de ficción (1997), nascemos na história e só depois, lentamente, descobrimos a natureza. Nessa historicidade primitiva - falsa historicidade que, sem fissuras e sem gretas, nos veda a perspectiva da morte - "a natureza é nossa primeira proibição e são necessários a aprendizagem e a experiência para descobrir que havia permanecido sempre aí (...)". Pois bem, para Saer, "a poesia busca na linguagem esses sedimentos, essas portas que persistem nela e permitem o acesso à natureza". (SAER,1997b:228)

"Para a conduta poética, a natureza (...) é um estranhamento. Assalta o poeta. Nesse estranhamento, o poeta realiza a negação da 
negação pela qual a história havia incorporado a natureza (...)". Essa negação da negação ocorre, por exemplo, no momento em que o escritor se dá conta de sua atividade de escritura; nesse instante ele se separa da história, fundindo-se na natureza. "(...) ficam unicamente a mão que se move, no silêncio, o som cru da pena e a gesticulação de uma escritura que não ressoa. [Nesses momentos] fundo-me, eu mesmo, no abismo da natureza", conclui o autor. (SAER, 1997b:229)

Saer nos transmite assim uma concepção da literatura, e não apenas da poesia, como "(...) uma disciplina da estranheza que borra tudo, que consome o mundo, o submerge na obscuridade e o resgata lavado e nítido para uma historicidade mais atual, menos primitiva". (SAER, 1997b:231)

O leitor é convidado a colocar em suspenso a leitura crítica e lingüística à medida que, ao trabalharem na "parede histórica", essas leituras se perdem nos preconceitos da razão. Propõe-se, então, que ele se abra a uma prosa poética que, fazendo surgir esses restos de natureza, produtores de frestas na história, "desencadeia o estranhamento". (SAER,1997b:230)

\section{2- Um pouco de realidade: uma estética das sensações}

Interrogado sobre o significado do termo 'real', que surge em vários de seus textos (e inclusive no título de um de seus romances, El limonero real), Saer diz fazer com esse termo uma "provocação" através da qual evidencia que não é possível esgotar o significante e, portanto, a narração, como acredita a concepção clássica de narração. Ele lembra ainda que "(...) a palavra real alude, por suposto, à realidade e por extensão ao realismo". (SAER,1997b:293-294) Sobre a realidade diz perceber que:

o conjunto da narração do século $\mathrm{XX}$ - incluindo aí o noveau roman - não nòs propõe nenhuma realidade fixa, 
inamovível, dada de uma vez para sempre, senão uma matéria imprecisa, flutuante, instável, que muda continuamente de forma, de valor, de lugar, uma realidade que se parece aos dados que possuímos dela antes da reflexão e da escritura, antes de formular estruturas epistemológicas destinadas a ordenar uma imagem dela. Que essa realidade seja anterior à linguagem ou inseparável dela, é um problema específico que requer uma estruturação narrativa adequada para sua formulação. (SAER, 1997b:184)

Já a questão do 'realismo literário' não deixa de suscitar a consideração de que não haveria um sentido preexistente a ser expresso pela linguagem, ou seja, um mundo externo instalado de modo nítido fora do sujeito, e passível de descrição tal como o concebe a narrativa clássica, em sua pretensão representativa ou imitativa. $\mathrm{O}$ ato de escrever surge como um puro ato de exteriorizarse, como um ato de invenção. "Não há, no princípio, nada", repete, uma dezena de vezes, o narrador de Ninguém, Nada, Nunca, como que a nos sugerir uma espécie de criação ex-nibilo.

Interrogando-se ainda sobre o 'realismo literário', Saer evoca 'a identidade absoluta do significado e do referente', tal como ocorre no 'riverrun' de Joyce. Ao estabelecer um fluxo contínuo entre as duas palavras 'river' (rio) e 'run' (corre), 'riverrun' (riocorre), Joyce nos transmitiria uma concepção heraclitiana - e realista da história, estabelecendo uma "identidade absoluta entre o rio e o ato de correr". (SAER, 1997b:178-182) No realismo literário de Saer teríamos, ao contrário, uma literatura que constrói um espaço vazio entre o significante e aquilo a que ele se refere; temos aí uma literatura que, negando o sujeito (Ninguém), o objeto (Nada) e até mesmo o tempo (Nunca), deixa em aberto a referência. Serão várias e diferenciadas as coisas que ocuparão, por um momento, o lugar central de referência.

Adentrando-nos um pouco mais na questão da 'realidade', em Ninguém, Nada, Nunca encontramos “(...) uma sucessão de 
imagens, semelhantes às de um estado intermediário entre o sono e a vigília".(SAER, 1997 a:165) Os personagens vivem em um estado sonambúlico que, às vezes, se duplica constituindo uma espécie de sonho dentro do sonho, presentificado na narrativa pelo mise en abyme. O calor de fevereiro, o "mês irreal", presentifica o real, em um dos sentidos dados por Jacques Lacan a esse termo, ou seja, - aquilo que não se consegue evitar, que retorna sempre ao mesmo lugar. Se essa temperatura de deserto, que chega a derreter o asfalto das ruas, produz uma "sensação de irrealidade", há também aqueles momentos em que "a tempestade pareceu espaIhar ao acaso, aqui e acolá, depois de dias e dias, um pouco de realidade." (SAER, 1997 a:165)

Esse 'asfalto derretido' não deixa de ser uma evocação evidente da realidade mencionada anteriormente como essa "(...) matéria imprecisa e flutuante, instável, que muda continuamente de forma, de valor, de lugar, (...) que se parece aos dados que possuímos dela antes da reflexão e da escritura...". (SAER, 1997b:184)

Em uma entrevista dada à Folha de São Paulo, em setembro de 1999, Saer afirma que, para ele, "o mundo é opaco, e os fatos e acontecimentos que nele ocorrem também o são". Essa opacidade é traduzida em seus livros de vários modos. Em Ninguém, Nada, Nunca esbarramos nela em alguns momentos em que o mundo se converte em "uma substância última e sem significado". (SAER, 1997 a:122) Tendo esbarrado aí, o sujeito da ficção saeriana "emerge, com dificuldade, de algo negro, sem forma, inominado"; sai "dessa submersão impensável, como de um pântano", (ibidem, 51), ele "se desempasta". (ibidem, 90)

Para os freqüentadores da Psicanálise esse espessamento do real não deixa de evocar Freud, no "Sonho da Injeção feita em Irma". Neste sonho, o real com o qual o sujeito se depara não é outro senão aquele de sua realidade carnal: "visão de angústia, identificação de angústia, última revelação do és isto"; "és isto", 
insiste Jacques Lacan, "que é o mais longínquo de ti, isto que é o mais informe". (LACAN, 1985:197-198). Diante dessa revelação o sujeito cai fora, se decompõe, se fragmenta, se pulveriza.

Se nó sonho o encontro do sujeito com esse 'espessamento do real' acaba resultando em uma escritura, a da fórmula de uma substância química, a trimetilamina, fórmula eminentemente simbólica; na ficção de Saer, - e faço aqui a minha hipótese de leitura - temos as descrições, a "minúcia obsessiva", e as repetições cumprindo essa função de formular de modo simbólico a realidade e, até mesmo, de dar um tratamento ao real. Sobre as descrições temos um comentário do próprio escritor, segundo o qual " (...) as coisas ganham realidade, uma realidade sem dúvida, que pertence mais a quem as descreve ou contempla do que às coisas propriamente ditas". (SAER, 1997 a:211). Quanto às repetições, graças a elas "(...) cada detalhe e o conjunto inteiro mudam, infinitesimais e bruscos, no espaço, de lugar". (ibidem,77)

A densidade do real com a qual o sujeito da ficção saeriana esbarra, seja ele o salva-vidas, o Gato ou Elisa, - personagens de Ninguém, Nada, Nunca - está presentificada de vários modos. Um deles é a sensação de ser "um organismo vivo", sensação assinalada ao longo de toda a narrativa através da presença de um cavalo, designado apenas 'baio': "(...) o grande corpo amarelado e palpitante, mais denso que eu, mais sólido, mais imerso na vida". (SAER, 1997 a:82) Constrói-se assim, ao longo do texto, uma "estética das sensações", tal como evidencia Bernardo Carvalho em seu instigante posfácio, uma estética que leva o sujeito "(...) à sensação de estar entre as coisas, de reconhecê-las uma a uma e de poder apalpá-las, sem mediações, em sua consistência real, alcançar a sua verdadeira matéria". (CARVALHO, 1997:230)

A sensação de ser, não exatamente um sujeito histórico, mas, um 'organismo vivo', um 'ser da natureza', - ou melhor, a sensação de ser um sujeito histórico com uma carga de natureza revelada - não ocorre sem atordoamento e esse atordoamento 
surge, na ficção de Saer, como um dos índices do espessamento do real. Ele assinala, em alguns momentos, o encontro do sujeito. com o gozo sexual e, também, com a sua posição de objeto no desejo do Outro. Temos, neste sentido, o encontro do Gato, na sua leitura de A filosofia na Alcova, com a "aspiração ao gozo infinito" experimentada pelos personagens sadianos (SAER,1997 a:170) e, em um outro momento, o "atordoamento" de Elisa quando, "(...) devido ao salto de seu sapato que ficou preso no asfalto fervente, viu-se inopinadamente de quatro no meio da rua, recolhendo um a um os objetos que saíram da bolsa de palha, dispersos a sua volta". (ibidem, 145)

O esbarrão no real tem, sobre os personagens saerianos, um efeito de fragmentação, de pulverização, tal como ocorre com o sujeito no sonho relatado por Freud. Enquanto o Gato tem a "impressão penosa de estar abandonado num fragmento qualquer de um espaço e de um tempo infinitos", (SAER, 1997 a:174) Elisa, por sua vez, "gira em círculo o dia inteiro sem nenhum objetivo", tentando "aliviar a pedra compacta que ocupa o lugar de sua mente". (ibidem, 138) Ela procura transpor uma sensação de flutuação na qual surgem "(...) os fragmentos de impressões e sensações remotas, como lembranças que não há jeito de encaixar umas nas outras para que formem um desenho claro e nítido". (ibidem,141)

Sobre esses personagens de Ninguém, Nada, Nunca podese dizer que eles não se apresentam na sua condição de sujeitos divididos entre o enunciado e a enunciação, entre o dito e o dizer; ou mesmo, aturdidos com as voltas do dito (l'etourdit), como diria Jacques Lacan. No entanto, eles evocam um outro comentário no qual o psicanalista francês apresenta o "sujeito como resposta do real", ou seja, como um modo de subjetivação de algo até então indizível, irrepresentável. Nesse sentido, é interessante o comentário do escritor argentino sobre os seus personagens em geral: 
meus personagens falam pouco. O silêncio que busco em meus livros é em certa medida a tradução dessa opacidade. Em suma, se relaciona com uma espécie de reserva de subjetividade. Mas não aquela subjetividade romântica, que partia da psicologia dos personagens. Não se trata de criar um tipo, um caráter, mas de conferir uma existência subjetiva a partir do que é silenciado. (SAER, Folha de São Paulo)

\section{Conclusão}

Ao lermos o texto de Juan José Saer pela via do 'espaço de pouca-realidade', que gera uma estética das sensações, nós o incluímos em uma série com a literatura surrealista de André Breton e com o sensacionismo de Fernando Pessoa, principalmente no seu Livro do desassossego. Esse espaço de pouca-realidade, estado intermediário entre o sonho e a vigília -, é privilegiado pelos surrealistas nas suas experimentações com a 'escrita automática' e está, até mesmo, designado no título de um dos textos de Breton: "Introduction au discours sur le peu de réalité" (1924). Em Pessoa, onde essa 'estética das sensações' é de fundamental importância, temos o escritor instalado em um espaço 'pardo' que estaria, segundo alguns, em relação direta com a categoria do 'neutro' que engendra o 'espaço literário'. Esse espaço, o escritor português o engendra mantendo à distância os estados de consciência claros e distintos, 'macroscópicos', e alargando o espaço intersticial, entre a vigília e o sono. Rejeitando o macroscópico e instalando-se nos interstícios, ele provoca o nascimento do 'microscópico', dando lugar a uma vida sensível, subjetiva, atravessada por acontecimentos extraordinários: acontecimentos de sensações. Aí, no intervalo dos interstícios, surgem as sensações finas, os 'milímetros' ou 'sensações de coisas mínimas'. (GIL,s/d:17-19) Se podemos localizar a poética de Saer entre essas poéticas do espaço de pouco-realidade - espaço que Jacques Lacan localizou 
entre o Imaginário e o Real e no qual constatou o surgimento de algo do campo pulsional e mesmo da fantasia -, o que a literatura do nosso escritor traz de específico é o modo, singularíssimo, no qual surge aí a "praxis da escritura". Trazendo ao texto a influência da interpretação musical, Saer diz que a perfeição formal da música desperta nele "a nostalgia de um relato que seja pura forma". Assim ele diz buscar, até o final de seus romances, "desprender-se dos acontecimentos para resolver-se na pura forma". (SAER, 1997b:296)

Teremos, portanto, no corpo mesmo do texto, - e creio residir aí o traço personalíssimo da praxis escritural de Saer - o trabalho do escritor no sentido de apurar as suas formas. O escrito surge então em sua dimensão 'plástica, pictórica, musical', tico em impressões como 'cheiros, rumores, apreensão, fulgurância, vida, morte' (como aquela dos cavalos que atravessa toda a narração de Ninguém, Nada, Nunca). (SAER,1998:291-298) Tal como afirma Mirta Stern, o ato de escritura apresenta-se aí como "(...) enquadre formal, como condição, como desencadeante da ficção". (STERN, s/d) A meu ver, ao surgir, intensa, no seu constante ato de re-escritura, a praxis escritural de Saer não deixa de nos evocar o oleiro que amassa o barro, para esculpir o pote.

Se Saer quer, como afirma em entrevistas e textos, que a sua seja uma 'literatura sem atributos', o leitor de seus livros não resistirá, entretanto, sob o efeito causado pela sua ficção, à tentação de dar a Ninguém, Nada, Nunca um atributo: atordoante!

Résumé: Cette article fait quelques commentaires sur la pratique de l'écriture de l'argentin Juan José Saer, en $y$ mettant en évidence une 'discipline de l'etrangement' et une 'estbétique des sensations' qui amenent le lecteur à l'etourdissement. Une attention special est donné au livre Ninguém, Nada, Nunca. 


\section{Referências Bibliográficas}

CARVALHO,B. Posfácio - "A leitura distraída". Ninguém, Nada, Nunca.(1980) São Paulo:Companhia das Letras, 1997.

CORBATTA, J. "Algunas notas sobre la 'praxis poética' de Juan José Saer. Revista Vuelta, México, out. 1999.

GIL, J. Fernando Pessoa, ou a metafísica das sensaçōes. Lisboa:Relógio d'Àgua, s/d.

LACAN, J. O eu na teoria de Freud e na técnica da psicanálise, O Seminário, Livro 2.

(1954-1955) R.J.:JZE, 1985.

PESSOA, F. Livro do desassossego. S.P.:Companhia das Letras, 2000.

SAER, J.J. Ninguém, nada, nunca.(1980) São Paulo:Companhia das Letras, 1997a.

Bs.As.:Ariel, 1997b.

. "El concepto de ficción"(1989) El concepto de ficción . "Notas sobre el noveau roman" (1972) El concepto de ficción Bs.As.:Ariel, 1997.

. "Sobre la poesia" (1968) El concepto de ficción Bs.As.:Ariel, 1997.

. "La selva espessa de lo real" (1979) El concepto de ficción Bs.As.:Ariel, 1997.

. "Una literatura sin atributos" (1980) El concepto de ficción Bs.As.:Ariel, 1997.

. "Entrevista realizada por Gerard Cortanze" El concepto de ficción Bs.As.:Ariel, 1997.

. "A arte de dizer menos". Entrevista realizada por Maurício Santana Dias, Folha de São Paulo, Caderno mais! 19 de setembro de 1999. STERN,M.E. "Juan José Saer: Construcción y teoria de la ficción narrativa". Hispamerica. Rev. de Literatura, n. ${ }^{\circ}$ 37. U.S.A.: Gaithersburg, s/d. 


\section{Bibliografia e Nota:}

BRETON,A. "Introducctión al Discurso sobre la poca realidad". Antologia. Mexico:Siglo Veintiuno, 1973.

LACAN, J. Os quatro conceitos fundamentais da psicanálise, O Seminário, Livro 11. Rio de Janeiro: JZE,1988. (Cf na p. 61 uma discussão sobre o "pouco de realidade")

. mais, ainda, O Seminário, Livro 20. Rio de Janeiro.:JZE,1982.

(Cf na p. 127 uma discussão sobre o "pouco de realidade")

MAIA, E.A "Escritura: na travessia da escrita". A força da letra. Estilo. Escrita. Representação. BRANCO, L. C. e BRANDÃO, R.S. (organizadoras). Belo Horizonte:Editora UFMG, 2000.

ROSA, M. "Direções da interpretação". Curinga, Revista da Escola Brasileira de Psicanálise-MG, B.H., $\mathrm{n}^{\circ}$ 7, abril de 1996.

\section{NOTA:}

Esse texto foi redigido a partir de leituras feitas no Seminário de Literaturas em Língua Portuguesa, coordenado pela Prof. Dra. Silvana Maria Pessôa de Oliveira, na Pós-Graduação em Letras: Estudos Literários da Faculdade de Letras da UFMG, 2001. 